\title{
Intensive low-glycaemic-load dietary intervention for the management of glycaemia and serum lipids among women with gestational diabetes: a randomized control trial
}

\author{
Wen-Jun Ma ${ }^{1}$, Zhi-Hong Huang ${ }^{1}$, Bi-Xia Huang ${ }^{2}$, Ben-Hua Qi ${ }^{1}$, Yan-Jun Zhang ${ }^{1}$, \\ Ben-Xi Xiao ${ }^{1}$, Yuan-Hong Li ${ }^{1}$, Li Chen ${ }^{2}$ and Hui-Lian Zhu ${ }^{2, *}$ \\ 'Guangdong General Hospital, Guangdong Academy of Medical Science, Guangzhou, People's Republic of China: \\ ${ }^{2}$ Faculty of Nutrition, School of Public Health, Sun Yat-sen University, 74th Zhongshan II Road, Guangzhou 510080, \\ People's Republic of China
}

Submitted 3 January 2014: Final revision received 18 July 2014: Accepted 13 August 2014: First published online 15 September 2014

\begin{abstract}
Objective: The present study aimed to compare the effects of a general dietary intervention and an intervention with low glycaemic load (GL) on glycaemic control, blood lipid metabolism and pregnancy outcomes in women with gestational diabetes mellitus.

Design: Participants were randomly assigned to two groups, receiving either an individualized general dietary intervention (Control group) or an intensive low-GL intervention (Low-GL group) every two weeks, from 24-26 weeks of gestation to delivery.

Setting: The Center of Maternal Primary Care in Guangdong General Hospital, China.

Subjects: Ninety-five women with gestational diabetes mellitus were enrolled from June 2008 to July 2009.

Results: After the intervention, both groups significantly decreased their dietary intakes of energy, fat and carbohydrate. The Low-GL group had significantly lower values for GL (122 v. 136) and glycaemic index (50v. 54) but greater dietary fibre intake $(33 v .29 \mathrm{~g} / \mathrm{d}$ ) than did the Control group (all $P<0 \cdot 01$ ). Significantly greater decreases in fasting plasma glucose $(-0.33 v$. $-0.02 \mathrm{mmol} / \mathrm{l}, P<0.01)$ and $2 \mathrm{~h}$ postprandial glucose $(-2.98 \quad v .-2.51 \mathrm{mmol} / 1, \quad P<0.01)$, significantly lower increases in total cholesterol $(0.12 v .0 .23 \mathrm{mmol} / \mathrm{l})$ and TAG $(0.41 v .0 .56 \mathrm{mmol} / \mathrm{l})$ and a significantly lower decrease in HDL cholesterol $(-0.01 v .-0.11 \mathrm{mmol} / \mathrm{l})$ were also observed in the Low-GL group compared with the Control group (all $P<0 \cdot 05$ ). There were no significant differences in body weight gain, birth weight or other maternal-fetal perinatal outcomes between the two groups.

Conclusions: The low-GL targeted dietary intervention outperformed the general dietary intervention in glycaemic control and the improvement of blood lipid levels in women with gestational diabetes mellitus.
\end{abstract}

Keywords Low-glycaemic-load intervention Gestational diabetes mellitus
Gestational diabetes mellitus (GDM), which occurs in approximately $1-5 \%$ of pregnancies in China ${ }^{(1)}$, is defined as any degree of glucose intolerance that emerges at the onset of pregnancy or is first recognized during pregnancy $^{(2)}$. Pregnant women diagnosed with GDM early in their pregnancies are at a higher risk of obstetric complications such as macrosomia, hydramnios, ketoacidosis, hypertension, preterm delivery and caesarean delivery ${ }^{(3)}$. Moreover, GDM increases the risk of subsequent type 2 diabetes for the mother and child later in life ${ }^{(3)}$. Due to a rapid increase in GDM incidence in China ${ }^{(4)}$, both prevention of the development of GDM and glycaemic control in GDM patients are urgently needed ${ }^{(1,5)}$.

Dietary intervention is considered the preferred treatment to achieve normal glucose levels and to control excessive fetal growth and other associated adverse outcomes in GDM patients $^{(6,7)}$. General dietary treatment measures for GDM patients are largely focused on controlling total energy intake and promoting consumption of foods with low fat content (particularly low saturated fat) and low glycaemic index (GI), with moderate restriction of carbohydrate ${ }^{(8)}$. One randomized controlled trial (RCT) has shown that a 
low-GI diet significantly reduced the need for the use of insulin in sixty-three GDM women ${ }^{(9)}$. Another RCT showed that a low-GI diet was more efficient in the control of postprandial glucose than the high-GI diet in forty-seven women with gestational hyperglycaemia ${ }^{(10)}$. Similar results were observed in patients with general type 2 diabetes mellitus ${ }^{(11)}$. The results of a systematic review of six RCT suggested that a low-GI diet more significantly decreased body mass, total fat, total cholesterol (TC) and LDL cholesterol (LDL-C) than other dietary programmes in overweight or obesity ${ }^{(12)}$. Another review also showed that a low-GI diet efficiently improved glycaemic control in diabetes without causing hypoglycaemic events ${ }^{(13)}$. These findings suggest that the low-GI diet might be a useful measure for glycaemic control and the improvement of other cardiovascular risk factors in GDM women.

However, there exist different results in related studies. One RCT in 107 GDM patients showed that a low-GI diet (compared with the intake of all types of carbohydrates with varying GI) was not more efficient in the improvement of glycaemic control ${ }^{(14)}$. Inconsistent results were observed in other studies ${ }^{(15)}$, possibly due to insufficient appreciation of the total amount of carbohydrate in the foods, which is the major determinant for blood glucose response.

Dietary glycaemic load (GL) was introduced to quantify the total glucose-increasing potential of carbohydratecontaining foods ${ }^{(16)}$. GL is calculated as the product of GI multiplied by the available carbohydrate proportion of the food ${ }^{(17)}$. Accumulating evidence has indicated that lowGL diets based on general dietary treatments are more promising educational intervention strategies in patients with diabetes because both GI and total consumption of carbohydrate are considered $^{(18)}$. However, limited evidence is available from GDM patients, especially among Asian or Chinese populations. A pilot RCT ( $n$ 46) demonstrated that a low-GL diet improved maternal cardiovascular risk factors compared with a low-fat diet ${ }^{(19)}$, which implies that a low-GL diet might be favourable to the outcomes of GDM. Further studies with larger sample size are warranted to evaluate whether a low-GL diet intervention during pregnancy would be more effective than other dietary intervention programmes.

The present study aimed to compare the effects of a low-GL dietary intervention and a general dietary intervention on glycaemic control and lipid metabolism in GDM women and on maternal and neonatal outcomes.

\section{Experimental methods}

\section{Study population}

In total, ninety-five participants were recruited for the current RCT by screening 2540 outpatients at the Center of Maternal Primary Care in Guangdong General Hospital, China, from June 2008 to July 2009. Eligible participants were required to be a resident of Guangzhou, the provincial capital of Guangdong; aged between 18 and 40 years; and an incident GDM patient diagnosed at 24-26 weeks of gestation. GDM patients were screened with a $50 \mathrm{~g}$ glucose challenge test according to the guidelines of the Chinese Medical Association $^{(20)}$ and the American Diabetes Association ${ }^{(21,22)}$. Positive cases (glucose concentration $\geq 7 \cdot 8 \mathrm{mmol} / \mathrm{l}$ following the glucose challenge test) were confirmed by further evaluation with a $3 \mathrm{~h}, 75 \mathrm{~g}$ oral glucose tolerance test and were diagnosed as GDM patients when they met at least two of the following criteria for glucose concentration at $0,1,2$ and $3 \mathrm{~h}$ post-load: fasting, $>5.8 \mathrm{mmol} / \mathrm{l} ; 1 \mathrm{~h},>10.6 \mathrm{mmol} / \mathrm{l} ; 2 \mathrm{~h}$, $>9.2 \mathrm{mmol} / \mathrm{l}$; and $3 \mathrm{~h},>8.1 \mathrm{mmol} / \mathrm{l}$. The exclusion criteria included: (i) pre-pregnancy diabetes; (ii) multiple gestations; (iii) other severe diseases, including hypertension, chronic hepatic and kidney disease and cancer; (iv) use of insulin or hypoglycaemic medications; (v) less than 9 years of formal schooling; and (vi) previous intensive nutrition education or intervention for diabetes. The study was conducted according to the guidelines laid down in the Declaration of Helsinki and all procedures involving human subjects/patients were approved by the Human Research Ethics Committee of Guangdong General Hospital. Written informed consent was obtained from all subjects/patients.

\section{Randomization and interventions}

Eligible participants were randomly assigned to one of the two arms according to odd/even random numbers generated by Excel $^{\circledR}$ software: the Control group and the low-glycaemic-load intervention (Low-GL) group. Both of these groups received a one-on-one general dietary intervention every two weeks according to the guidelines recommended by the Chinese Medical Association ${ }^{(20)}$ from 24-26 gestational weeks until delivery, which was usually 12-14 weeks later. The general dietary intervention was made via detailed advice and the provision of sample daily menus that mainly targeted limitations on starches and fat and encouraged appropriate macronutrient proportion ranges. The recommended daily energy intake was approximately $146 \mathrm{~kJ}$ (35 kcal)/ $\mathrm{kg}$ per d for individuals with a normal weight and $104 \mathrm{~kJ}(25 \mathrm{kcal}) / \mathrm{kg}$ per $\mathrm{d}$ for obese women (BMI $\geq 28 \mathrm{~kg} / \mathrm{m}^{2}$ ) according to their pre-pregnancy weight $^{(20,23)}$. The percentages of energy from carbohydrate, protein and fat were controlled to $45-50 \%, 20-24 \%$ and $25-30 \%$, respectively. Five to six meals daily with smaller portions were also recommended.

In addition to general dietary advice, the participants enrolled in our study also received instruction on the glycaemic effects of food. These individuals were given an exchange list from which they selected their starch choice or serving (Control or Low-GL). The exchange lists were designed based on the key foods strategy. The lists provided to the control group comprised intermediate- to high-GL foods, which represent the typical Guangzhou diet, whereas the lists provided to the Low-GL group contained low-GL foods. Because milk products, vegetables and 
fruits are recommended for pregnant women to maintain fetal growth and development, participants were also given advice on the GL of starchy fruits and vegetables high in starch. The GL value of each food was obtained from an internationally published GL table ${ }^{(24)}$ and the food composition table of China $(2002)^{(25)}$. The average GI/GL values for each participant were calculated ${ }^{(26)}$ as follows:

$$
\begin{aligned}
& \text { Mean GI }=\sum(\text { food GI } \times \text { amount of carbohydrate } \\
& \text { contained in a specified food)/total } \\
& \text { amount of carbohydrate }
\end{aligned}
$$

and

$$
\text { Mean GL }=\sum(\text { food GI } \times \text { amount of carbohydrate }
$$

Each participant received one copy of Dietary Guidance Handbook for GDM Women, which compiles specific advice. The handbooks for the Control and Low-GL groups had the same cover, format and length but contained different exchange lists on food GL. Dietitians assessed dietary intakes using a $3 \mathrm{~d}$ recall to assess the compliance once every two weeks and reinforced the intervention at each visit. The exact content of the intervention was altered to meet individual needs, based on dietary details and weight growth between the two interventions.

All participants were asked not to consume alcohol or dietary supplements or medications that could influence glucose tolerance and lipid metabolism and were told to maintain their usual exercise patterns during the study.

\section{Dietary intake assessments}

Habitual dietary intake pre-treatment and during the interventional period was assessed with an FFQ using the reference times of the past year at baseline and of the intervention period at the end of the intervention ${ }^{(27)}$. Dietary intake was calculated according to the 2002 China food composition table ${ }^{(25)}$.

\section{Outcome measurements}

The primary outcomes were fasting plasma glucose (FPG; mmol/l) and glycated $\mathrm{Hb}(\mathrm{HbA} 1 \mathrm{c} ; \%)$ and $2 \mathrm{~h}$ postprandial blood glucose (2 h PG; mmol/l). Secondary outcomes included fasting serum lipid levels, body weight, BMI and gestational outcomes (such as preterm delivery, macrosomia, intra-uterine asphyxia, eclampsia, postpartum haemorrhage and perinatal infection).

Venous or postprandial blood samples were collected before and after the intervention at admission to the hospital for delivery. Serum was separated by a centrifugation procedure $(3000 \mathrm{rpm}$ for $10 \mathrm{~min}$ ) after clotting at room temperature. The samples were processed and analysed by the Central Laboratory of Guangdong General Hospital.

Glucose levels were determined by the oxidase method within $2 \mathrm{~h}$ after sampling. Glucose, TC, TAG, HDL cholesterol (HDL-C) and LDL-C were assessed using an LX-20 automatic biochemical analyser (Beckman Coulter Trifel). HbA1c levels were assessed by HPLC. The interassay $\mathrm{CV}$ ranged between $2 \cdot 0 \%$ and $5 \cdot 0 \%$.

Pre-pregnancy weight was self-reported on the first day of prenatal care. Body weight and height were measured with the participants wearing only undergarments.

\section{Statistical analysis}

The statistical software package SPSS 13.0 was used to analyse the data. The data are reported as mean and standard deviation, or as number and percentage. The $t$ test or $\chi^{2}$ test or Fisher's exact test were used for the comparisons of baseline characteristics. Differences in mean changes (follow-up value minus baseline value) in the outcomes over the intervention period and differences in other continuous data between the two arms were examined using a $t$ test for normally distributed data or Wilcoxon's rank test for non-normally distributed data. A modified intention-to-treat principle including all participants who completed the baseline and follow-up assessments was used in the analysis of the primary outcomes as done in a previous report ${ }^{(28)}$. All $P$ values were two-sided. The level of significance was set at $P<0.05$.

\section{Results}

\section{Demographic characteristic of the participants}

Of the ninety-five GDM participants, eighty-three completed the entire intervention and data collection processes, whereas the other twelve dropped out and did not complete post-intervention tests for the following reasons: six could not comply with the dietary schedule, three needed insulin treatment due to blood glucose that they could not control properly, one experienced pre-eclampsia, one experienced severe gestational hypertension and one refused to continue the study for an unexplained reason. There were no differences in demographic characteristics or pre-intervention metabolic measurements between completers and dropouts. The study flow chart is shown in Fig. 1.

The demographic characteristics of the sample are shown in Table 1 . The majority of participants (89\%) had a college degree or higher. Most participants (95\%) had no adverse reproductive history and $76 \%$ had no family history of diabetes. There were no significant differences in age, pre-pregnancy BMI, educational attainment, family history of diabetes, gestational week at diagnosis and at enrolment in the intervention, and adverse reproductive history between the two groups at baseline (all $P>0.05$ ).

\section{Daily intakes of energy and macronutrients before and after the intervention}

No significant differences were observed between the two groups in the dietary intakes of energy, protein, fat or carbohydrate, or in dietary fibre, or in dietary GI or GL at baseline (Table 2). After the intervention, the intake 


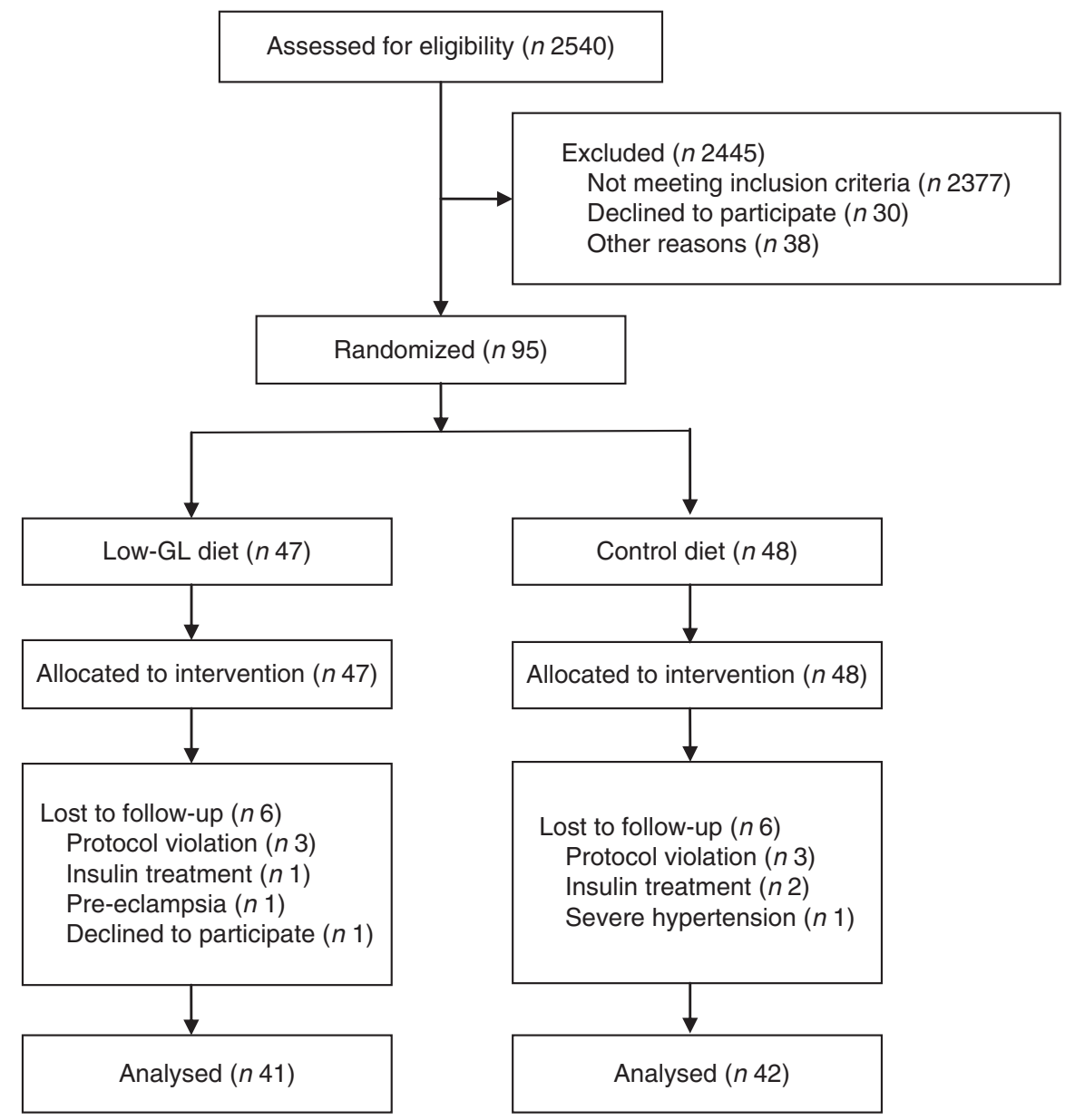

Fig. 1 The study flow diagram

Table 1 Baseline characteristics of the study participants: women with gestational diabetes mellitus recruited at the Center of Maternal Primary Care in Guangdong General Hospital, China, from June 2008 to July 2009

\begin{tabular}{|c|c|c|c|c|c|}
\hline \multirow[b]{2}{*}{ Characteristic } & \multicolumn{2}{|c|}{ Control group ( $n$ 42) } & \multicolumn{2}{|c|}{ Low-GL group ( $n$ 41) } & \multirow[b]{2}{*}{$P$} \\
\hline & Mean or $n$ & SD or $\%$ & Mean or $n$ & SD or $\%$ & \\
\hline Age (years), mean and SD & $30 \cdot 0$ & 3.5 & $30 \cdot 1$ & 3.8 & 0.901 \\
\hline Pre-pregnancy BMI $\left(\mathrm{kg} / \mathrm{m}^{2}\right)$, mean and SD & $21 \cdot 15$ & $2 \cdot 75$ & 21.90 & 3.14 & 0.250 \\
\hline $\mathrm{BMI} \geq 24 \mathrm{~kg} / \mathrm{m}^{2 *}, n$ and $\%$ & 7 & 17 & 9 & 21 & 0.542 \\
\hline Education level* $^{*}$ & & & & & 0.970 \\
\hline$>$ College education, $n$ and $\%$ & 37 & 88 & 37 & 90 & \\
\hline Gestational week at diagnosis (weeks), mean and SD & $25 \cdot 6$ & 0.8 & $25 \cdot 8$ & 0.7 & 0.229 \\
\hline $\begin{array}{l}\text { Gestational week at intervention (weeks), mean and SD } \\
\text { Family history of diabetes* }\end{array}$ & $27 \cdot 9$ & $1 \cdot 1$ & $27 \cdot 5$ & $1 \cdot 1$ & $\begin{array}{l}0.102 \\
0.276\end{array}$ \\
\hline Yes, $n$ and \% & 8 & 19 & 12 & 29 & \\
\hline Adverse reproductive history* & & & & & 0.626 \\
\hline Yes, $n$ and $\%$ & 3 & 7 & 1 & 2 & \\
\hline
\end{tabular}

GL, glycaemic load.

${ }^{*}$ The $x^{2}$ test was used for the group comparisons. For the others, the $t$ test was used.

of energy of all participants dropped by approximately $21 \%$. The greatest reduction occurred in carbohydrate intake (approximately 28\%, $P<0.01$ ), followed by the intake of fat (approximately $15 \%, P<0.01$ ) and protein (approximately 10\%, $P<0 \cdot 01$ ). GI and GL in both groups decreased as well. GI decreased by $2.3(\mathrm{SD} 0.2)$ in the Control group and by $5.9(\mathrm{SD} 0.2)$ in the Low-GL group $(P<0.01)$, and GL decreased by 62.6 (sD 5.2$)$ in the Control group and by $67 \cdot 4$ (sD $6 \cdot 2)$ in the Low-GL group $(P<0 \cdot 01)$. After the intervention, the Low-GL group had significantly 
Table 2 Intakes of energy and macronutrients and the values of GI and GL before and after the dietary intervention according to study group: women with gestational diabetes mellitus recruited at the Center of Maternal Primary Care in Guangdong General Hospital, China, from June 2008 to July 2009

\begin{tabular}{|c|c|c|c|c|c|c|c|c|c|c|c|c|c|c|c|}
\hline & \multicolumn{5}{|c|}{ Pre-intervention } & \multicolumn{5}{|c|}{ Post-intervention } & \multicolumn{5}{|c|}{ Mean change } \\
\hline & \multicolumn{2}{|c|}{$\begin{array}{c}\text { Control group } \\
(n 42)\end{array}$} & \multicolumn{2}{|c|}{$\begin{array}{l}\text { Low-GL group } \\
\quad(n 41)\end{array}$} & \multirow[b]{2}{*}{$P$} & \multicolumn{2}{|c|}{$\begin{array}{l}\text { Control group } \\
\qquad(n 42)\end{array}$} & \multicolumn{2}{|c|}{$\begin{array}{c}\text { Low-GL group } \\
(n 41)\end{array}$} & \multirow[b]{2}{*}{$P$} & \multicolumn{2}{|c|}{$\begin{array}{l}\text { Control group } \\
\quad(n 42)\end{array}$} & \multicolumn{2}{|c|}{$\begin{array}{l}\text { Low-GL group } \\
\quad(n 41)\end{array}$} & \multirow[b]{2}{*}{$P$} \\
\hline & Mean & SD & Mean & SD & & Mean & SD & Mean & SD & & Mean & SD & Mean & SD & \\
\hline Ene & $10 \cdot 7$ & 1.8 & $10 \cdot 8$ & $2 \cdot 0$ & 0.811 & 8.5 & 0.9 & 8.4 & 0.9 & 0.614 & $-2 \cdot 2$ & 0.4 & $-2 \cdot 4$ & 0.6 & 0.077 \\
\hline Protein $(\mathrm{g})^{*}$ & $102 \cdot 9$ & $23 \cdot 3$ & $105 \cdot 2$ & $23 \cdot 4$ & 0.655 & $95 \cdot 6$ & $12 \cdot 5$ & 94.6 & $14 \cdot 3$ & 0.735 & -7.3 & $6 \cdot 8$ & $-10 \cdot 6$ & $9 \cdot 2$ & 0.066 \\
\hline Fat $(\mathrm{g})^{*}$ & 83.2 & $15 \cdot 5$ & 85.9 & 13.9 & 0.406 & 71.8 & $8 \cdot 6$ & 71.6 & 9.1 & 0.918 & -11.4 & 8.4 & $-14 \cdot 3$ & 7.5 & $0 \cdot 101$ \\
\hline Carbohydrate $(\mathrm{g})^{*}$ & 353.9 & 83.5 & $338 \cdot 2$ & $75 \cdot 0$ & 0.371 & 252.6 & 34.5 & 243.6 & 35.5 & 0.245 & $-101 \cdot 3$ & $18 \cdot 2$ & -94.6 & $16 \cdot 5$ & 0.083 \\
\hline Dietary fibre $(\mathrm{g})^{\star}$ & 35.5 & 8.7 & $35 \cdot 3$ & 9.6 & 0.921 & 28.7 & $5 \cdot 6$ & 33.3 & $6 \cdot 1$ & $<0.01$ & $-6 \cdot 8$ & 4.8 & -2.0 & 4.9 & $<0.01$ \\
\hline $\mathrm{Gl}$ & $56 \cdot 1$ & $2 \cdot 4$ & $56 \cdot 0$ & $2 \cdot 1$ & 0.841 & 53.8 & 2.5 & $50 \cdot 1$ & $2 \cdot 2$ & $<0.01$ & $-2 \cdot 3$ & 0.2 & -5.9 & 0.2 & $<0.01$ \\
\hline $\mathrm{GL}^{*}$ & 198.5 & $46 \cdot 8$ & $189 \cdot 4$ & $42 \cdot 0$ & 0.354 & 135.9 & $19 \cdot 0$ & $122 \cdot 0$ & $17 \cdot 8$ & $<0.01$ & -62.6 & $5 \cdot \overline{2}$ & -67.4 & $6 \cdot 2$ & $<0.01$ \\
\hline
\end{tabular}

GI, glycaemic index; GL, glycaemic load.

The Control group received an individualized general dietary intervention and the Low-GL group received an intensive low-GL intervention, every two weeks, from 24-26 weeks of gestation to delivery.

*Wilcoxon's rank test was used for the group comparisons. For the others, the $t$ test was used.

Table 3 Metabolic outcomes before and after the dietary intervention according to study group: women with gestational diabetes mellitus recruited at the Center of Maternal Primary Care in Guangdong General Hospital, China, from June 2008 to July 2009

\begin{tabular}{|c|c|c|c|c|c|c|c|c|c|c|c|c|c|c|c|c|}
\hline & \multicolumn{5}{|c|}{ Pre-intervention } & \multicolumn{5}{|c|}{ Post-intervention } & \multicolumn{5}{|c|}{ Mean change } & \multirow[b]{3}{*}{ Power } \\
\hline & \multicolumn{2}{|c|}{$\begin{array}{l}\text { Control } \\
\text { group } \\
(n 42)\end{array}$} & \multicolumn{2}{|c|}{$\begin{array}{l}\text { Low-GL } \\
\text { group } \\
(n 41)\end{array}$} & \multirow[b]{2}{*}{$P$} & \multicolumn{2}{|c|}{$\begin{array}{l}\text { Control } \\
\text { group } \\
(n \text { 42) }\end{array}$} & \multicolumn{2}{|c|}{$\begin{array}{l}\text { Low-GL } \\
\text { group } \\
(n 41)\end{array}$} & \multirow[b]{2}{*}{$P$} & \multicolumn{2}{|c|}{$\begin{array}{l}\text { Control } \\
\text { group } \\
(n 42)\end{array}$} & \multicolumn{2}{|c|}{$\begin{array}{l}\text { Low-GL } \\
\text { group } \\
(n 41)\end{array}$} & \multirow[b]{2}{*}{$P$} & \\
\hline & Mean & SD & Mean & SD & & Mean & SD & Mean & SD & & Mean & SD & Mean & SD & & \\
\hline FPG (mmol/l) & 4.80 & 0.55 & 4.96 & 0.81 & 0.295 & 4.78 & 0.91 & 4.63 & 0.97 & 0.469 & -0.02 & 0.22 & -0.33 & 0.21 & $<0.01$ & 1.000 \\
\hline $2 \mathrm{~h}$ PG (mmol/l) & $9 \cdot 37$ & 1.35 & $9 \cdot 13$ & 1.61 & 0.463 & $6 \cdot 86$ & $1 \cdot 25$ & $6 \cdot 15$ & 1.07 & 0.007 & -2.51 & 0.66 & -2.98 & 0.75 & 0.003 & 0.857 \\
\hline $\mathrm{HbA1c}(\%)$ & 5.58 & 0.30 & 5.56 & 0.58 & 0.843 & $5 \cdot 67$ & 0.28 & $5 \cdot 68$ & 0.54 & 0.916 & 0.09 & 0.14 & 0.12 & 0.14 & 0.332 & 0.164 \\
\hline $\mathrm{TC}(\mathrm{mmol} / \mathrm{l})$ & 5.74 & 0.74 & 5.79 & 1.01 & 0.797 & 5.97 & 0.89 & 5.96 & 1.02 & 0.962 & 0.23 & 0.09 & 0.12 & 0.09 & $<0.01$ & 0.999 \\
\hline $\mathrm{TG}(\mathrm{mmol} / \mathrm{l})^{*}$ & $2 \cdot 60$ & 0.60 & $2 \cdot 67$ & $1 \cdot 27$ & 0.748 & 3.14 & 1.05 & 3.09 & 1.14 & 0.836 & 0.56 & 0.12 & 0.41 & 0.13 & $<0.01$ & 0.999 \\
\hline HDL-C $\left(\mathrm{mmol} / \mathrm{l}^{*}\right.$ & 1.96 & 0.39 & 1.89 & 0.33 & 0.381 & 1.85 & 0.36 & 1.87 & 0.34 & 0.795 & -0.11 & 0.09 & -0.01 & 0.10 & $<0.01$ & 0.998 \\
\hline LDL-C $\left(\mathrm{mmol} / \mathrm{I}^{*}\right.$ & $2 \cdot 13$ & 0.60 & $2 \cdot 19$ & 0.58 & 0.645 & $2 \cdot 16$ & 0.81 & $2 \cdot 20$ & 0.54 & 0.792 & 0.01 & 0.06 & 0.03 & 0.07 & 0.166 & 0.797 \\
\hline
\end{tabular}

GL, glycaemic load; FPG, fasting plasma glucose; $2 \mathrm{~h} \mathrm{PG}, 2 \mathrm{~h}$ postprandial glucose; HbA1c, glycated Hb; TC, total cholesterol; HDL-C, HDL cholesterol; LDL-C, LDL cholesterol.

The Control group received an individualized general dietary intervention and the Low-GL group received an intensive low-GL intervention, every two weeks, from 24-26 weeks of gestation to delivery.

*Wilcoxon's rank test was used for the group comparisons. For the others, the $t$ test was used.

lower values of GL (122 v. 136) and GI (50v. 54) but greater dietary fibre $(33 v .29 \mathrm{~g} / \mathrm{d})$ than did the Control group (all $P<0 \cdot 01)$. No significant differences were observed in the dietary intakes of energy, protein, fat or carbohydrate between the two groups (Table 2). There was no significant difference in the intakes of micronutrients between the two groups before and after the intervention (data not shown).

\section{Comparison of mean changes in blood metabolic outcomes}

As shown in Table 3, there were no significant differences in the metabolic outcomes at baseline (all $P>0.05$ ). After the intervention, significantly greater decreases in FPG $(-0.33$ v. $-0.02 \mathrm{mmol} / \mathrm{l}, P<0.01)$ and $2 \mathrm{~h} \mathrm{PG}(-2.98 v$. $-2.51 \mathrm{mmol} / 1, \quad P<0.01)$ were observed in the Low-GL group compared with the Control group. Significantly lower increases in TC $(0.12 v \cdot 0.23 \mathrm{mmol} / \mathrm{l})$ and TAG $(0.41 v$.
$0.56 \mathrm{mmol} / \mathrm{l}$ ) and a significantly lower decrease in HDL-C $(-0.01 v .-0.11 \mathrm{mmol} / \mathrm{l})$ were also observed in the Low-GL group compared with the Control group (all $P<0.05$ ). Our study had a power of over 0.85 to detect the abovementioned differences at a significance level of 0.05 . However, no significant difference was observed in the mean changes of HbA1c and LDL-C between the two groups over the intervention period $(P>0.05)$.

\section{Maternal-fetal outcomes}

Total weight gain and its average value per week, as well as the birth weight of infants were similar in the two groups (all $P>0 \cdot 50$ ). There was no significant difference in the incidence of maternal-fetal perinatal outcomes, including preterm delivery, macrosomia, intra-uterine asphyxia, postpartum haemorrhage and infection, between the two arms (all $P>0.70$; Table 4). 
Table 4 Maternal-fetal perinatal outcomes after the dietary intervention according to study group: women with gestational diabetes mellitus recruited at the Center of Maternal Primary Care in Guangdong General Hospital, China, from June 2008 to July 2009

\begin{tabular}{|c|c|c|c|c|c|}
\hline & \multicolumn{2}{|c|}{ Control group ( $n$ 42) } & \multicolumn{2}{|c|}{ Low-GL group ( $n 41)$} & \multirow[b]{2}{*}{$P$} \\
\hline & Mean & SD & Mean & SD & \\
\hline Total weight gain $(\mathrm{kg})$ & $14 \cdot 72$ & 3.46 & $14 \cdot 25$ & 4.41 & 0.592 \\
\hline Weekly weight gain $(\mathrm{kg})$ & 0.38 & 0.09 & 0.37 & 0.11 & 0.758 \\
\hline \multirow[t]{2}{*}{ Birth weight $(\mathrm{kg})$} & $3 \cdot 30$ & 0.44 & $3 \cdot 24$ & 0.46 & 0.572 \\
\hline & $n$ & $\%$ & $n$ & $\%$ & \\
\hline Preterm delivery* & 6 & 14.29 & 4 & 9.76 & 0.738 \\
\hline Macrosomia* & 2 & 4.76 & 1 & 2.44 & 0.983 \\
\hline Intra-uterine asphyxia* & 2 & 4.76 & 3 & $7 \cdot 31$ & 0.978 \\
\hline Eclampsia* & 1 & $2 \cdot 38$ & 0 & 0.00 & 0.990 \\
\hline Postpartum haemorrhage ${ }^{*}$ & 2 & 4.76 & 2 & 4.88 & 0.980 \\
\hline Infection* & 1 & $2 \cdot 38$ & 0 & 0.00 & 0.990 \\
\hline
\end{tabular}

GL, glycaemic load.

The Control group received an individualized general dietary intervention and the Low-GL group received an intensive low-GL intervention, every two weeks, from 24-26 weeks of gestation to delivery.

${ }^{*}$ Fisher's exact test was used for the group comparisons. For the others, the $t$ test was used.

\section{Discussion}

The present RCT found that a low-GL (with higher dietary fibre) intervention significantly improved FPG, 2 h PG and fasting TC, TAG and HDL-C compared with a general dietary intervention in GDM. Our findings suggest that a low-GL targeted dietary intervention is more effective for improving glycaemic control and lipid levels in GDM women.

Based on these study observations, the improvements in metabolic outcomes of the Low-GL group were promising. The study found significantly larger reductions in FPG and $2 \mathrm{~h}$ PG in GDM women who were prescribed a low-GL diet compared with a high-GL diet, and had an isoenergetic intake and the same carbohydrate intake. A previous study that explored blood glucose control by a low-GI diet in women with gestational hyperglycaemia also demonstrated that more participants achieved their postprandial glucose target on a low-GI diet $(58.4 \%)$ than on a control diet $(48.7 \%, P<0.001)^{(10)}$. The advantage for diabetes control in the present study was observed despite a lack of significant differences in HbA1c between the two groups.

HbA1c is the 'good criterion' for measuring the effect of diabetes treatment ${ }^{(29)}$. Based on our study's observations, however, we found that HbA1c increased, but not significantly, in these two groups after a 10- to 12-week diet intervention compared with baseline. Similarly, a 12-month randomized controlled comparison of low-GI, high-GI and low-carbohydrate diets in patients with type 2 diabetes found no differences between the groups in $\mathrm{HbAlc}^{(30)}$. Christensen et al. ${ }^{(31)}$ performed medical nutrition therapy with or without fruit restriction in type 2 diabetics for 12 weeks and also found no difference in HbA1c between the groups. However, a meta-analysis including interventions that ranged in duration between 1 and 12 months found that low-GI and low-GL diets had $0.3-0.5 \%$ greater reductions in HbA1c than those observed for higher-GI or
higher-GL alternatives ${ }^{(13)}$. HbA1c serves as a marker for average blood glucose levels over the previous months prior to the measurement. The cause of disagreements between these studies and our results are complicated and may be explained by the short time that we monitored HbA1c. The short-term intervention (10-12 weeks) in our study may not have allowed sufficient time to observe significant changes in HbA1c. Thus, longer-term monitoring is necessary for determining the efficacy of the nutrition advice.

We found that the intake of total energy assessed by the FFQ at baseline was more than $10 \mathrm{MJ} / \mathrm{d}$ in our participants, exceeding the amount $(8.8 \mathrm{MJ} / \mathrm{d})$ recommended by Chinese dietary reference intakes. In addition to the high energy intake, the greater intakes of carbohydrate and fat than recommended by the dietary reference intakes might partially explain the development of impaired insulin sensitivity, as suggested by recent epidemiological studies ${ }^{(32)}$. The present study found that general dietary intervention might have a positive impact on the dietary behaviours of individuals. In both the Control and the Low-GL groups, the dietary intakes of energy, fat and carbohydrate decreased significantly after the intervention. Moreover, the Low-GL group outperformed the Control group in reducing the intake of dietary GI and GL and in increasing dietary fibre. A previous Asian trial also documented similar improvements in dietary quality (increasing intake of dietary fibre) in the low-GI arm as compared with conventional recommendations in patients with type 2 diabetes mellitus ${ }^{(33)}$.

We also examined the effects of the low-GL dietary intervention on maternal-fetal outcomes and found similar effects on total weight gain and its average value per week and the birth weight of infants compared with the general dietary intervention. Our findings suggested that the lowGL dietary intervention did not decrease fetal growth and did not increase the incidence of adverse pregnant events (e.g. preterm delivery, macrosomia, intra-uterine asphyxia and postpartum haemorrhage). The present results are in 
accordance with the findings of another RCT, which investigated the effects of a low-GI diet on pregnancy outcomes in $\mathrm{GDM}^{(34)}$. The present study found that although the low-GI diet achieved a modestly lower GI, there was no significant difference in birth weight or the prevalence of macrosomia and adverse pregnancy outcomes. However, it should be acknowledged that we did not have sufficient power to detect a difference in the risk of these adverse pregnant events due to limited study size.

Although the validity and reproducibility of the FFQ has been addressed for the participants ${ }^{(27)}$, the GI/GL of the FFQ was not validated. However, the validity and reproducibility of the food components are closely correlated to each other in an FFQ because these components are calculated using the same food items. In the FFQ, GI/GL has a similar characteristic to those of macronutrients (e.g. carbohydrate, protein, etc.) and energy. It is unlikely that the validity and/or reproducibility are poor for GI/GL when macronutrients and energy have similar and good values of validity (FFQ $v .24 \mathrm{~h}$ recalls, $r=0.53$ to 0.66$)^{(35)}$.

The study was a behavioural intervention study rather than a double-blinded RCT. Both the researchers (the dietitians) and the participants could not be blinded to the group status. We did not use allocation concealment, either. However, to minimize researcher biases, the treatment guidelines for both groups were standardized, all involved dietitians received the same training before the interventions, and the involved dietitians and other researchers (gynaecologists and laboratory technicians) were blinded to the assessments of metabolic results and maternal-fetal outcomes. We observed a lower energy intake but greater weight gain after the intervention as compared with the baseline values. Habitual energy intake might be under-reported or underestimated during the intervention period. Finally, we could not differentiate the effects between the low-GI/GL diet and high dietary fibre in our study, because the low GI/GL value may be caused by a high content of dietary fibre in the diets.

\section{Conclusion}

In conclusion, the low-GL targeted dietary intervention outperformed the general dietary intervention in glycaemic control and the improvement of blood lipid levels in GDM women. The low-GL intervention is safe in terms of fetal growth.

\section{Acknowledgements}

Acknowledgements: The authors thank all the study participants for their contribution. They also thank Professor Yu-Ming Chen, Department of Epidemiology, Sun Yat-sen University of Medical Sciences, China, for the help with the statistical analysis. Financial support: This study was jointly supported by Science and Technology Program of Guangdong Province, China (grant number 2006B36005013). The funder had no role in the design, analysis or writing of this article. Conflict of interest: None. Authorship: W.-J.M. and Z.-H.H. were the principal investigators and data collectors; B.-X.H., B.-H.Q. and Y.-J.Z. participated in recruiting pregnant women, providing dietary advice and the follow-up survey; B.-X.X. presided at laboratory detection; Y.-H.L. was in charge of physical measurements; L.C. carried out data collection; H.-L.Z. was responsible for the study design and writing the manuscript. All authors were responsible for the critical revision of the manuscript. Ethics of human subject participation: The Human Research Ethics Committee of Guangdong General Hospital approved all procedures (number $2009104 \mathrm{H}$ ).

\section{References}

1. Wei Y, Yang H \& Gao X (2008) Investigation into the prevalence and suitable diagnostic criteria of gestational diabetes mellitus in China. Zhonghua Fu Chan Ke Za Zhi 43, 647.

2. Buchanan TA \& Xiang AH (2005) Gestational diabetes mellitus. J Clin Invest 115, 485-491.

3. Yang X, Hsu-Hage B, Zhang $\mathrm{H}$ et al. (2002) Women with impaired glucose tolerance during pregnancy have significantly poor pregnancy outcomes. Diabetes Care $\mathbf{2 5}$, 1619-1624.

4. Zhang F, Dong L, Zhang CP et al. (2011) Increasing prevalence of gestational diabetes mellitus in Chinese women from 1999 to 2008. Diabet Med 28, 652-657.

5. Case J, Willoughby D, Haley-Zitlin V et al. (2006) Preventing type 2 diabetes after gestational diabetes. Diabetes Educ 32, 877-886.

6. Crowther CA, Hiller JE, Moss JR et al. (2005) Effect of treatment of gestational diabetes mellitus on pregnancy outcomes. N Engl J Med 352, 2477-2486.

7. Evans E \& Patry R (2004) Management of gestational diabetes mellitus and pharmacists' role in patient education. Am J Health Syst Pharm 61, 1460-1465.

8. Louie JC, Brand-Miller JC \& Moses RG (2013) Carbohydrates, glycemic index, and pregnancy outcomes in gestational diabetes. Curr Diab Rep 13, 6-11.

9. Gunderson EP (2004) Gestational diabetes and nutritional recommendations. Curr Diab Rep 4, 377-386.

10. Grant SM, Wolever T, O'Connor DL et al. (2011) Effect of a low glycaemic index diet on blood glucose in women with gestational hyperglycaemia. Diabetes Res Clin Pract 91, 15-22.

11. Monro JA (2002) Glycaemic glucose equivalent: combining carbohydrate content, quantity and glycaemic index of foods for precision in glycaemia management. Asia Pac I Clin Nutr 11, 217-225.

12. Thomas D, Elliott E \& Baur L (2007) Low glycaemic index or low glycaemic load diets for overweight and obesity. Cochrane Database Syst Rev issue 3, CD005105.

13. Thomas D \& Elliott EJ (2009) Low glycaemic index, or low glycaemic load, diets for diabetes mellitus. Cochrane Database Syst Rev issue 1, CD006296.

14. Perichart-Perera O, Balas-Nakash M, Rodríguez-Cano A et al. (2012) Low glycemic index carbohydrates versus all types of carbohydrates for treating diabetes in pregnancy: a randomized clinical trial to evaluate the effect of glycemic control. Int J Endocrinol 2012, 296097.

15. Moreno-Castilla C, Hernandez M, Bergua M et al. (2013) Low-carbohydrate diet for the treatment of gestational 
diabetes mellitus: a randomized controlled trial. Diabetes Care 36, 2233-2238.

16. Salmeron J, Manson JE, Stampfer MJ et al. (1997) Dietary fiber, glycemic load, and risk of non-insulin-dependent diabetes mellitus in women. JAMA 277, 472-477.

17. Lajous M, Boutron-Ruault M-C, Fabre A et al. (2008) Carbohydrate intake, glycemic index, glycemic load, and risk of postmenopausal breast cancer in a prospective study of French women. Am J Clin Nutr 87, 1384-1391.

18. Miller CK, Edwards L, Kissling G et al. (2002) Evaluation of a theory-based nutrition intervention for older adults with diabetes mellitus. J Am Diet Assoc 102, 1069-1081.

19. Rhodes ET, Pawlak DB, Takoudes TC et al. (2010) Effects of a low-glycemic load diet in overweight and obese pregnant women: a pilot randomized controlled trial. Am J Clin Nutr 92, 1306-1315.

20. Obstetrics Unit of Obstetrics and Gynecology Branch, Chinese Medical Association (2007) Guidelines for recommendations of clinical diagnosis and treatment for GDM (draft). Chin J Pract Gynecol Obstet 23, 475-477.

21. National Diabetes Data Group (1979) Classification and diagnosis of diabetes mellitus and other categories of glucose intolerance. Diabetes 28, 1039-1057.

22. American Diabetes Association (2004) Gestational diabetes mellitus. Diabetes Care 27, Suppl. 1, S88-S90.

23. Bei-Fan Z (2002) Predictive values of body mass index and waist circumference for risk factors of certain related diseases in Chinese adults: study on optimal cut-off points of body mass index and waist circumference in Chinese adults. Asia Pac J Clin Nutr 11, Suppl. 8, S685-S693.

24. Foster-Powell K, Holt SH \& Brand-Miller JC (2002) International table of glycemic index and glycemic load values: 2002. Am J Clin Nutr 76, 5-56.

25. Yang Y, Wang G \& Pan X (2002) China Food Composition 2002. Beijing: Peking University Medical Press.
26. van Woudenbergh GJ, Kuijsten A, Sijbrands EJ et al. (2011) Glycemic index and glycemic load and their association with C-reactive protein and incident type 2 diabetes. $J$ Nutr Metab 2011, 623076.

27. Zhang C-X \& Ho SC (2009) Validity and reproducibility of a food frequency questionnaire among Chinese women in Guangdong province. Asia Pac J Clin Nutr 18, 240-250.

28. Kreijkamp-Kaspers S, Kok L, Grobbee DE et al. (2004) Effect of soy protein containing isoflavones on cognitive function, bone mineral density, and plasma lipids in postmenopausal women. JAMA 292, 65-74.

29. Goldstein DE, Little RR, Lorenz RA et al. (2004) Tests of glycemia in diabetes. Diabetes Care 27, 1761-1773.

30. Wolever TM, Gibbs AL, Mehling C et al. (2008) The Canadian Trial of Carbohydrates in Diabetes (CCD), a 1-y controlled trial of low-glycemic-index dietary carbohydrate in type 2 diabetes: no effect on glycated hemoglobin but reduction in C-reactive protein. Am J Clin Nutr 87, 114-125.

31. Christensen AS, Viggers L, Hasselström K et al. (2013) Effect of fruit restriction on glycemic control in patients with type 2 diabetes - a randomized trial. Nutr J 12, 29.

32. Saldana TM, Siega-Riz AM \& Adair LS (2004) Effect of macronutrient intake on the development of glucose intolerance during pregnancy. Am J Clin Nutr 79, 479-486.

33. Barakatun Nisak MY, Ruzita AT, Norimah AK et al. (2010) Improvement of dietary quality with the aid of a low glycemic index diet in Asian patients with type 2 diabetes mellitus. J Am Coll Nutr 29, 161-170.

34. Louie JCY, Markovic TP, Perera N et al. (2011) A randomized controlled trial investigating the effects of a low-glycemic index diet on pregnancy outcomes in gestational diabetes mellitus. Diabetes Care 34, 2341-2346.

35. Shu XO, Yang G, Jin F et al. (2004) Validity and reproducibility of the food frequency questionnaire used in the Shanghai Women's Health Study. Eur J Clin Nutr 58, 17-23. 